\title{
HTLV-I associated uveitis revisited: characteristic grey-white, granular deposits on retinal vessels
}

\author{
Kumiko Nakao, Norio Ohba
}

\begin{abstract}
Aims-To elucidate whether there exists any clinical sign characteristic of HTLV-I associated uveitis.

Methods-Fifty five patients with HTLV-I associated uveitis were reviewed. These cases had serum antibodies to HTLV-I, and any other uveitis entities were carefully excluded by means of clinical and laboratory studies.

Results-Eight cases (14.5\%) developed vascular lesions in the retina, characterised by grey-white, granular deposits scattered on the retinal veins and/or arteries in the posterior pole. The vascular changes did not accompany any haemorrhage, sheathing, or leakage of fluorescent dye on angiograms, and the retina was otherwise unremarkable. A single or clustered form of similar materials was also found to deposit on the vitreoretinal interface of the foveolar area. These deposits resolved in a few weeks spontaneously or in response to corticosteroids together with anterior uveal inflammation.

Conclusion-The vascular lesions described here suggest a characteristic sign for HTLV-I associated uveitis, and it may provide, if recognised, an additional clinical marker to establish diagnosis.

(Br f Ophthalmol 1996;80:719-722)
\end{abstract}

HTLV-I associated uveitis (HAU) is an inflammatory disease of the uvea that is associated with human $T$ cell lymphotropic virus type 1 (HTLV-I). ${ }^{1}$ Epidemiological and clinical studies have revealed that the disease is more prevalent in endemic areas of the retrovirus, ${ }^{2} 3$ and that its clinical picture is characterised by the following factors. (1) Middle aged adults of either sex infected with HTLV-I present with acute, granulomatous, or non-granulomatous uveal involvements. (2) Inflammatory lesions are usually mild or moderate, resolve in a few weeks in response to corticosteroids, and result in favourable visual outcome. (3) The disease affects one or both eyes, and it is recurrent in about half of cases. (4) The disease may develop as an isolated ocular disorder, or it is accompanied by HTLV-I associated myelopathy that is a distinct neurological disease caused by HTLV-I. ${ }^{4}$

The majority of HTLV-I infected individuals remain asymptomatic throughout life, and the prevalence of HAU is estimated to be about one in 1000-2000 HTLV-I carriers. ${ }^{6}$ Therefore, particularly in endemic areas, coincidence of HTLV-I infection is possible among patients with other distinct uveitis entities. Furthermore, diagnosis of HAU is on the basis of exclusion of other aetiologies, together with presence of serum antibodies to HTLV-I; elaborate laboratory assessment of affected aqueous humour to study local synthesis of HTLV-I antibodies ${ }^{7}$ or HTLV-I infected lymphocytes $^{89}$ is usually not acceptable because of the mild nature of the disease. It is, therefore, justified to elucidate whether there is any clinical marker that may provide a diagnostic aid for HAU. We report here characteristic, grey-white, granular deposits that are scattered on the major retinal vessels and on the vitreoretinal interface over the foveolar area.

\section{Patients and methods}

We reviewed a consecutive series of 55 patients with HAU who were seen between January 1988 and June 1995 at the Kagoshima University Hospital, located in the southwestern area of Japan, in which HTLV-I is highly endemic. These cases were diagnosed as HAU, since they had serum antibodies to HTLV-I and any other uveitis entities were excluded by means of a battery of systemic and laboratory examinations. Ocular examination consisted of full physical and ophthalmic history, applanation tonometry, slit-lamp biomicroscopy with a three mirror contact lens, and binocular ophthalmoscopy. A fluorescein fundus angiogram was obtained in selected patients after receiving informed consent.

\section{Results}

A series of 55 patients with HAU showed acute, mild to moderate, granulomatous, or non-granulomatous inflammatory lesions, which involved predominantly the anterior uvea. Eight patients $(14.5 \%)$ of the series were remarkable in that they showed, in addition to inflammatory signs in the anterior uvea, such characteristic changes in the retinal vasculatures as those described below. Their clinical data are summarised in Table 1.

The eight patients, four males and four females, developed ocular disease as adults (mean age 39 years; range 20-61 years). Laboratory tests for uveitis were unremarkable, except for serum antibodies to HTLV-I. Three cases had an isolated ocular disease, and the other five cases were affected with HTLV-I associated myelopathy or hyperthyroidism for which the retrovirus is thought to play an underlying role. ${ }^{510}$

These patients complained of acute floaters or blurred vision, and presented with mild, granulomatous inflammatory lesions in the 
Table 1 Clinical information of eight cases of HTLV-I associated uveitis with characteristic retinal vascular changes

\begin{tabular}{|c|c|c|c|c|c|c|c|c|c|c|c|c|c|c|c|c|}
\hline Case & $\begin{array}{l}\text { Age } \\
\text { (years)/ } \\
\text { sex }\end{array}$ & $\begin{array}{l}\text { Systemic } \\
\text { disease }\end{array}$ & $\begin{array}{l}\text { HTLV-I } \\
\text { serum } \\
\text { titre }\end{array}$ & $\begin{array}{l}\text { Affected } \\
\text { eye }\end{array}$ & $\begin{array}{l}\text { Keratic } \\
\text { precipitates }\end{array}$ & $\begin{array}{l}\text { Aqueous } \\
\text { cells }\end{array}$ & $\begin{array}{l}\text { Iris } \\
\text { nodules }\end{array}$ & $\begin{array}{l}\text { Vitreous } \\
\text { opacities }\end{array}$ & $\begin{array}{l}\text { Granular } \\
\text { deposits } \\
\text { on retinal } \\
\text { vessels }\end{array}$ & $\begin{array}{l}\text { Granular } \\
\text { deposits } \\
\text { on the } \\
\text { fovea }\end{array}$ & $\begin{array}{l}\text { r Fluorescein } \\
\text { staining } \\
\text { of retinal } \\
\text { vessels }\end{array}$ & $\begin{array}{l}\text { Corticosteroids } \\
\text { regimen }\end{array}$ & $\begin{array}{l}\text { Weeks to } \\
\text { resolution } \\
\text { of } \\
\text { granule }\end{array}$ & $\begin{array}{l}\text { Initial } \\
\text { visual } \\
\text { acuity }\end{array}$ & $\begin{array}{l}\text { Final } \\
\text { visual } \\
\text { acuity }\end{array}$ & $\begin{array}{l}\text { Recur } \\
\text { rence }\end{array}$ \\
\hline 1 & $28 / \mathrm{F}$ & HAM & 512 & $\mathbf{R}$ & - & $1+$ & - & Granular & + & + & ND & Topical & 2 & 0.7 & 1.0 & - \\
\hline 2 & $46 / M$ & - & 512 & $\mathrm{R} / \mathrm{L}$ & Granular & $2+$ & - & Granular & + & + & ND & Topical & 1 & $\begin{array}{l}0.9 / \\
0.2\end{array}$ & $\begin{array}{l}0.7 / \\
0.7\end{array}$ & - \\
\hline 3 & $43 / M$ & - & 512 & $\mathbf{R}$ & - & $1+$ & - & $\begin{array}{l}\text { Fine/ } \\
\text { granular }\end{array}$ & + & + & Minimum & Systemic & 4 & 0.7 & 1.2 & - \\
\hline 4 & $33 / \mathrm{M}$ & HAM & 8192 & $\mathbf{R}$ & Granular & $3+$ & Koeppe & $\begin{array}{l}\text { Membr- } \\
\text { anous/ } \\
\text { granular }\end{array}$ & + & $?$ & Minimum & Systemic & 3 & 0.5 & 0.7 & + \\
\hline 5 & $20 / M$ & $\begin{array}{l}\text { Hyper- } \\
\text { thyroidism }\end{array}$ & 256 & $\mathrm{R} / \mathrm{L}$ & Granular & $2+$ & Koeppe & Granular & + & + & ND & Systemic & 2 & $\begin{array}{l}0.3 / \\
0.1\end{array}$ & $\begin{array}{l}0.7 / \\
0.3\end{array}$ & + \\
\hline 6 & $48 / F$ & $\begin{array}{l}\text { Hyper- } \\
\text { thyroidism }\end{array}$ & 2048 & L & Fine & $2+$ & Koeppe & $\begin{array}{l}\text { Fine/ } \\
\text { granular }\end{array}$ & + & + & ND & Topical & 3 & 0.3 & 1.2 & - \\
\hline 7 & $36 / F$ & - & 8192 & $\mathbf{R}$ & Granular & $2+$ & Koeppe & $\begin{array}{l}\text { Fine/ } \\
\text { granular }\end{array}$ & + & + & Minimum & Systemic & 3 & 0.3 & 1.0 & - \\
\hline 8 & $61 / F$ & $\begin{array}{l}\text { Hyper- } \\
\text { thyroidism }\end{array}$ & 256 & $\mathrm{R} / \mathrm{L}$ & Granular & $1+$ & Koeppe & $\begin{array}{l}\text { Fine/ } \\
\text { granular }\end{array}$ & + & + & Minimum & Systemic & 2 & $\begin{array}{l}1.2 / \\
0.5\end{array}$ & $\begin{array}{l}1.2 / \\
1.2\end{array}$ & - \\
\hline
\end{tabular}

HAM = HTLV-I associated myelopathy; ND = not done; ? = uncertain because of vitreous opacity.

anterior uvea, including grey-white granular materials over the back of the corneal endothelium, grey-white Koeppe nodule-like deposits on the pupillary margin, and granular vitreous opacifications of varying densities.

Ophthalmoscopic examination revealed changes in the retinal vasculature in the posterior fundus. On the surface of the major retinal vessels there were deposits of grey-white, discrete, round material. Typical deposits were scattered over retinal veins, and sometimes over retinal arteries as well, without any accompanying vascular sheathing or haemorrhage. A single or clustered lesion of similar features was also present on the vitreoretinal interface corresponding to the foveolar area. The relevant posterior vitreous membrane was not detached, and the materials appeared to be located on the internal limiting membrane. The feature of the characteristic depositions appeared similar to that of keratic precipitates, iris nodules, and granular vitreous opacities. Noticeably, the retina and the choroid were otherwise intact. Fluorescein angiograms available in some of the patients who gave informed consent were also unremarkable, except for a minimum staining of relevant vessel walls without any marked leakage of fluorescent dye.

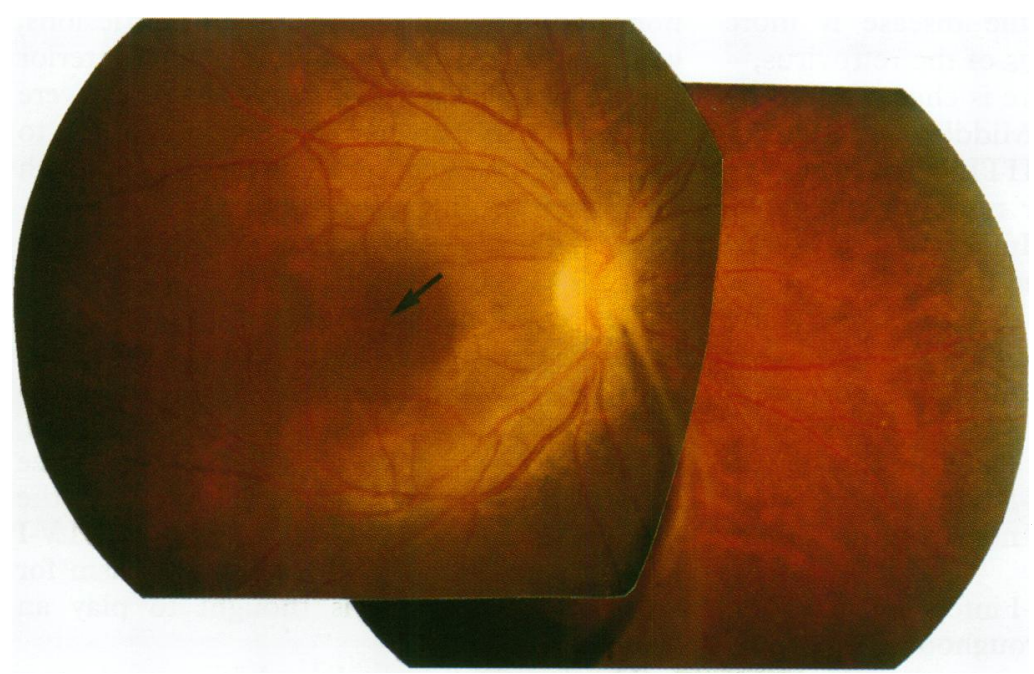

Figure 1 Case 1 in Table 1. Numerous grey-white granular materials are deposited on the surface of retinal vessels and retina. Similar depositions are also clustered on the foveola (arrow).
The retinal vascular deposits as well as uveal inflammations resolved over 1-4 weeks spontaneously or in seeming response to corticosteroids, leaving no clinical trace. The ocular disease occurred unilaterally or bilaterally. Two of the eight cases had recurrent ocular disease during a follow up period over 3 years; each episode was similar to that in the initial event.

It should be noted that the characteristic depositions on the retinal vessels, mentioned above, were not observed in any of 318 patients, with various distinct uveitis entities or aetiologically undefined uveitis, who were seen by the present authors during the same period.

\section{REPORT OF CASES}

Case 1

A 28-year-old woman, who had suffered from HTLV-I associated myelopathy beginning as early as 11 years old, presented with a 2 week history of blurred vision in the right eye. Corrected visual acuity was 0.7 in the right eye. Minimum inflammatory cells were present in the anterior chamber. The anterior chamber angle was unremarkable, and intraocular pressure was normal. There were grey-white strands extended from the optic disc and a few granular opacities in the posterior vitreous cavity. Numerous grey-white granular materials were found to deposit on the posterior retina, most prominent on the surface of retinal veins and arteries (Fig 1). Topical corticosteroids were administered, and 2 weeks later the retinal vessel lesions as well as anterior uveal reactions resolved almost completely.

\section{Case 2}

A 46-year-old man presented with a 2 week history of floaters in both eyes, preceded by slight fever. On examination, he appeared physically normal. Corrected visual acuity was 0.9 in the right eye and 0.2 in the left. There were grey-white granular keratic precipitates and inflammatory cells in the anterior chambers, with normal anterior chamber angles and intraocular pressures. There were a few granular opacities in the posterior vitreous cavity. Fundus examination revealed deposition of grey-white granular material on slightly distended retinal veins and arteries in the 

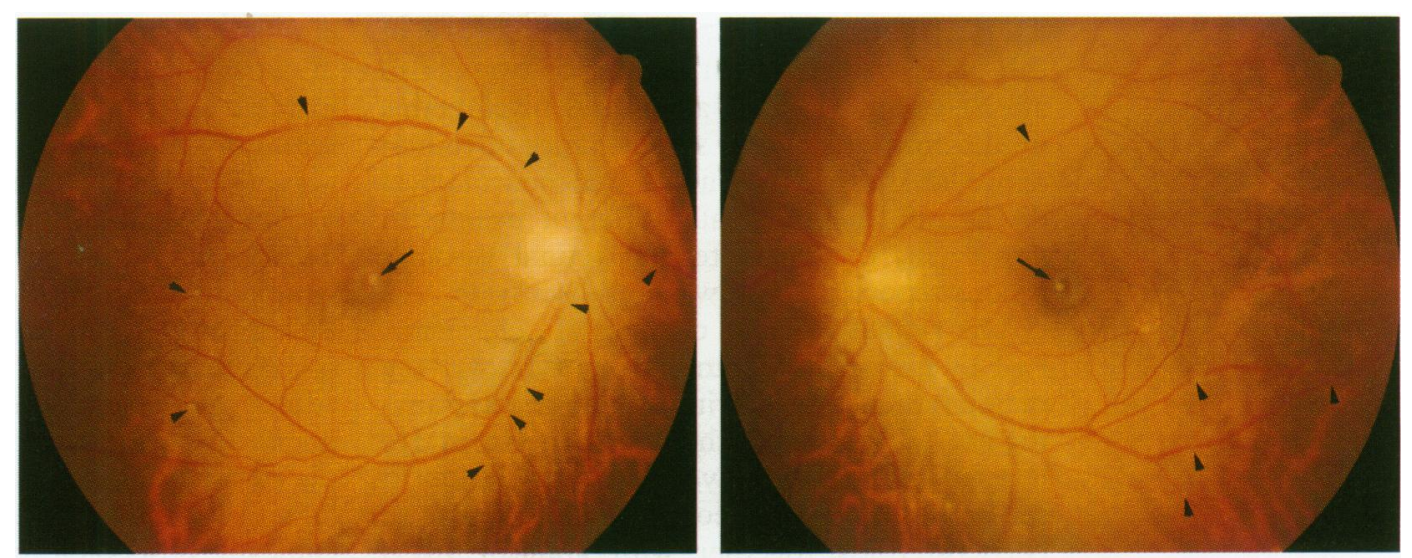

Figure 2 Case 2 in Table 1. In both eyes, there are depositions of grey-white granules on the slightly dilated retinal vessels in the posterior fundus (arrowhead). Deposition of a relatively large granule on the fovea is also seen (arrow). White ring around the fovea is a photographic artefact.

posterior fundus and on the vitreoretinal interface over the centre of the fovea. The retinochoroid was otherwise unremarkable (Fig 2). The anterior uveal inflammations and granular materials over retinal vessels resolved after 1 week's topical corticosteroids.

Case 3

A 43-year-old man presented with acute blurred vision in the right eye. Corrected visual acuity was 0.7 in the right eye. There were inflammatory cells in the anterior chamber and granular opacities in the vitreous cavity. Ophthalmoscopy revealed grey-white, discrete granules deposited on dilated retinal vessels in the posterior pole. At the vitreoretinal interface corresponding to the foveola, there were small white granules, similar in colour, contour, and shape to those on the retinal vessels (Fig 3A). Fluorescein angiography revealed a minimum staining of the posterior retinal veins with dot hypofluorescence corresponding to the greywhite deposits (Fig 3B). The patient was treated with systemic corticosteroids. Four weeks later, the anterior uveal inflammatory signs and retinal vascular changes had disappeared (Fig 3C).

\section{Discussion}

The clinical features of HAU are not disease specific as reported previously, ${ }^{45}$ so that evidence for serum antibodies to HTLV-I does not readily lead to a definite diagnosis, in particular in such endemic areas as southern Japan. In fact, we have experienced not a few patients with distinct uveitis entities, such as Behçet's disease, who had a coincident infection with HTLV-I. ${ }^{2}$ Moreover, specific laboratory tests to examine local synthesis of antibodies to HTLV-I or to prove presence of HTLV-I infected T lymphocytes in the aqueous humour are not feasible, because the disease is mild to moderate with resolution in a few weeks and hence informed consent for aspiration of the aqueous humour is rarely obtained. It is, therefore, possible that, although distinct uveitis entities were carefully excluded by means of a battery of clinical and laboratory examinations, all of the present series of 55 patients do not represent HAU but a coincidence of aetiologically different uveitis.
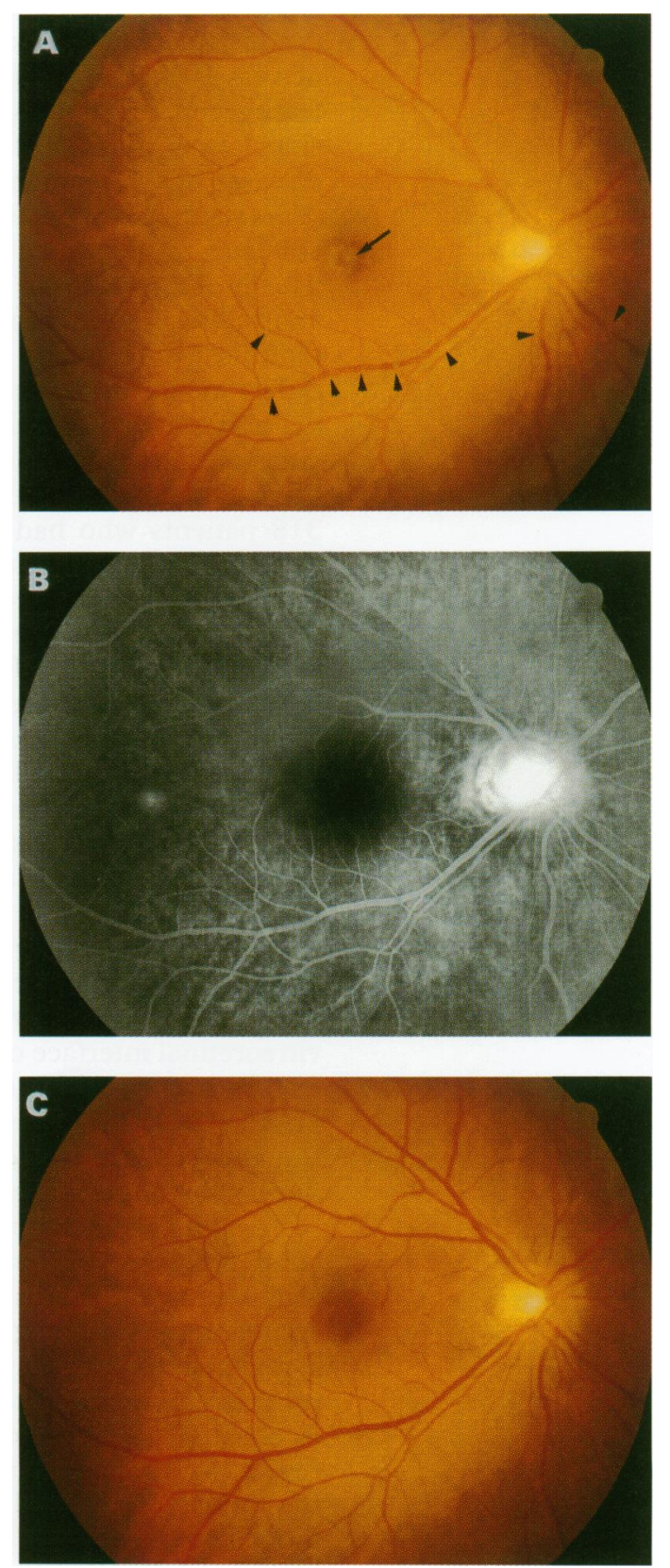

Figure 3 Case 3 in Table 1. (A) Deposition of white granules on the posterior dilated retinal vessels (arrowhead) granules on the posterior dilated retinal vessels (arrowhead)
and the fovea (arrow) is seen. (B) Fluorescein angiogram reveals a slight staining of posterior retinal vein and hyperfluorescence of the optic disc, but no leakage of fluorescent dye. (C) Four weeks later, the granular deposits have been resolved. 
Thus, it is emphasised, above all, that two of the eight patients with the lesion were also affected with HTLV-I associated myelopathy, implicating a negligibly small chance of coincidence of the HTLV-I associated neurological disease and aetiologically different uveitis. In any event, the characteristic retinal vascular lesions reported above warrant discussion.

The retinal vascular changes are characterised by grey-white, granular deposits over the major retinal vessels without any accompanying haemorrhage, sheathing, or fluorescent dye leakage on angiography, and by resolution in several weeks spontaneously or in response to corticosteroids together with anterior uveal lesions. Retinal vasculitis or phlebitis is frequently associated with distinct uveitis entities including sarcoidosis and toxoplasmic retinochoroiditis in the peripheral and/or posterior fundus, and usually accompanied by sheathing of vessels, haemorrhage, and fluorescent dye leakage on the fluorescein angiogram. Occasional cases of ocular toxoplasmosis and other diseases show segmental retinal periarteritis, characterised by white patches or plaques adherent to the retinal arteries which are most usually associated with active lesions of retinochoroiditis and remain up to several months. ${ }^{11}{ }^{12}$ Thus, the vascular lesion in HAU differs in all features from such segmental retinal periarteritis. The characteristic retinal vascular changes were observed in eight $(14.5 \%)$ of 55 patients with HAU, but not in any of our 318 patients who had uveitis associated with various diseases including sarcoidosis and toxoplasmosis. Hence, it is likely that the retinal vascular changes reported here provide a clinical marker for HAU. It should, however, be mentioned that the characteristic vascular lesion was not very common among patients with HAU, because all of the 55 patients were not 'true HAU' or alternatively, but not mutually exclusively, because such lesions were not recognised at the time of examination owing to the short duration.

It is also intriguing that deposition of the characteristic granular material occurred not only on the retinal vessels but also on the vitreoretinal interface of the foveolar area. This feature may provide an additional marker for HAU, although the mechanism through which the granules are limited to the centre of the fundus remains to be elucidated.

It is noticeable that the characteristic vascular depositions are not associated with vessel wall damage demonstrable with fluorescein angiography. Pathological studies of HTLV-I associated myelopathy (HAM), a chronic progressive neurological disease that has been established to be associated with HTLV-I, ${ }^{13}$ reveal perivascular cuffing of lymphocytes in the spinal cord. ${ }^{14}{ }^{15}$ The level of circulating intercellular adhesion molecules and the adherence of $T$ cells to vascular endothelial cells are shown to increase in patients with HAM,${ }^{16}{ }^{17}$ which accounts for the initial event of lymphocyte migration from the blood to the central nervous system. Increased autologous or spontaneous proliferative reaction of periph- eral blood lymphocytes in patients with HAM in vitro suggests that extravascular HTLV-I infected $\mathrm{T}$ lymphocytes are free from serum inhibitors and liable to proliferate in the central nervous system. ${ }^{18-20}$ Assessment of the aqueous humour of patients with HAU provides evidence for infiltration of HTLV-I infected T lymphocytes into the anterior chamber. ${ }^{89}$ Referring to these findings, it is tempting to speculate that HTLV-I infected T lymphocytes adhere to the endothelium of retinal vessels, migrate into the vitreous cavity, proliferate in the manner of autologous or spontaneous proliferative reaction, and eventually result in the clinically observable characteristic grey-white material. This study was supported by grants in aid for scientific research to $\mathrm{KN}$ (project numbers $03771230 ; 04771361$; 05771413 ; $06771514)$ from
Culture of Japan.

1 Nakao K, Matsumoto M, Ohba N. Noninfectious anterio uveitis in patients infected with human T-lymphotropic uveitis in patients infected with human T-ly
virus type I. $尹$ pn $₹$ Ophthalmol 1989;33:472-81.

2 Nakao $K$, Ohba N, Matsumoto $M$. Seroprevalence of antibodies to HTLV-I in patients with ocular disorders. $B$ f Ophthalmol 1991;75:76-8.

3 Ohba N, Nakao K, Isashiki Y, Osame M, Sonoda S, Yashiki $\mathrm{S}$, et al. A multicenter case-control study of HTLV-Iassociated uveitis. Fpn f Ophthalmol 1994;38:162-7.

4 Nakao K, Ohba N. Clinical features of HTLV-I associated uveitis. Br F Ophthalmol 1993;77:274-9.

5 Ohba N, Nakao K, Isashiki Y, Kaminagayoshi T, Sonoda S Yashiki S, et al. Clinical features of HTLV-I-associated uveitis determined in multicenter collaborative study. $f_{p n} \mathcal{F}$ uveitis determined in multicent

6 Nakao K, Ohba N. Prevalence of endogenous uveitis in Kagoshima prefecture, southwest Japan. $\mathcal{F}$ fpn Ophthalmol Soc 1996;100:150-5.

7 Nakao K, Isashiki Y, Uto M, Ohba N, Kawano K. Antibodies to HTLV-I in the aqueous humor of HTLV-I associated uveitis. $\mathcal{F}$ fpn Ophthalmol Soc 1994;98:866-71.

8 Mochizuki M, Watanabe T, Yamaguchi K, Yoshimura $K$ Nakashima S, Shirao M, et al. Uveitis associated with human T-cell lymphotropic virus type-I. Am $\mathcal{f}$ Ophthalmol 1992;114:123-9.

9 Sagawa K, Mochizuki M, Masuoka K, Katagiri K, Katayama T, Maeda T, et al. Immunopathological mechanisms of human T cell lymphotropic virus type 1 (HTLV-I) nisms of human T cell lymphotropic

10 Nakao K, Ohba N, Otsuka S, Okubo A, Yanagita T, Hashimoto $\mathrm{N}$, et al. HTLV-I associated uveitis and hyperthyroidism. Fpn f Ophthalmol 1994;38:56-61.

11 Schlaegel TF. Ocular toxoplasmosis and pars planitis. New York: Grune and Stratton, 1978:80-3.

12 Griffin AG, Bodian M. Segmental retinal periarteritis: report of three cases. Am $\mathcal{F}$ Ophthalmol 1956;47:544-8.

13 Osame M, Matsumoto M, Usuku K, Izumo S, Ijichi N, Amitani $\mathrm{H}$, et al. Chronic progressive myelopathy associated with elevated antibodies to human T-lymphotropic virus type 1 and adult T-cell leukemia-like cells. Ann Neurol virus type 1 and ad
$1987 ; 21: 117-22$.

14 Akizuki S, Nakazato O, Higuchi Y, Tanabe K, Setoguchi M, Yoshida S, et al. Necropsy findings in HTLV-I associated myelopathy. Lancet 1987;i:156-7.

15 Iwasaki Y. Pathology of chronic myelopathy associated with HTLV-I infection (HAM/TSP). F Neurol Sci 1990;96:10323.

16 Tsukada N, Miyagi $K$, Matsuda $M$, Yanagisawa $N$. Increased levels of circulating intercellular adhesion molecule-1 in multiple sclerosis and human T-lymphotropic virus type I-associated myelopathy. Ann Neurol 1993;33:646-9.

17 Ichinose K, Nakamura T, Kawakami A, Eguchi K, Nagasato $\mathrm{K}$, Shibayama $\mathrm{K}$, et al. Increased adherence of T cells to human endothelial cells in patients with human T-cell lymhuman endothelial cells in patients with human T-cell lymphotropic virus

18 Usuku K, Sonoda S, Osame M, Yashiki S, Takahashi K Matsumoto $\mathrm{M}$, et al. HLA haplotype-linked high immun responsiveness against HTLV-I in HTLV-I-associated myelopathy: comparison with adult T-cell leukemia/ ymphoma. Ann Neurol 1988;23 (Suppl):S143-50.

19 Itoyama Y, Minato S, Kira J, Goto I, Sato H, Okochi K, et al. Spontaneous proliferation of peripheral blood lymphocytes increased in patients with HTLV-I- associated myelopathy. Neurology 1988;38:1302-7.

20 Ijichi S, Eiraku N, Osame $M$, Izumo S, Kubota $R$, Maruyama I, et al. Hypothetical pathogenesis of HAM/ TSP: occurrence of proliferative response of lymphocytes in the central nervous system. In: Román GC, Vernant JC in the central nervous system. In: Román GC, Vernant JC,
Osame $\mathrm{M}$, eds. $H T L V-I$ and the nervous system. New York: Liss, 1989:337-42. 